\title{
Design and evaluation of an improved microwave-based thermal nebulizer for liquid sample introduction in inductively coupled plasma atomic emission spectrometry
}

\author{
Guillermo Grindlay,* Luis Gras, Juan Mora and Vicente Hernandis \\ Received 11th May 2007, Accepted 10th July 2007 \\ First published as an Advance Article on the web 3rd August 2007 \\ DOI: $10.1039 /$ b707161b
}

A re-designed microwave-based thermal nebulizer (MWTN) that overcomes all the drawbacks shown by previous prototypes (i.e. lack of robustness, poor heating efficiency) is presented. The new device employs an optimized $\mathrm{TM}_{010}$ cavity and nozzle design. MWTN performance was evaluated in inductively coupled plasma atomic emission spectrometry (ICP-AES) and compared to that provided by a concentric pneumatic nebulizer. Current MWTN design improves sample heating efficiency and system robustness. As a consequence, a 10 times lower matrix concentration than previous designs can be employed. The minimum inorganic (i.e. acids and salts) and organic (i.e. alcohols) concentrations required to nebulize are 0.25 and $40 \% \mathrm{w} / \mathrm{w}$, respectively. The influence of microwave power $(180-290 \mathrm{~W})$, matrix nature (acids, salts and organics), sample uptake rate $\left(0.9-1.8 \mathrm{~mL} \mathrm{~min}^{-1}\right)$ and nebulizer critical dimensions, such as nozzle and PTFE capillary internal diameter (150-300 and 300-800 $\mu \mathrm{m})$ and PTFE capillary length $(50-150 \mathrm{~cm})$ on the behaviour of the MWTN was studied. Optimum operating conditions for this nebulizer are obtained employing high microwave powers, matrix concentration and sample uptake rate, as well as nozzle and PTFE capillary with a narrow internal diameter. Although the MWTN behavior depends on the samples physical properties, aerosol drop size distributions and analyte transport rate for inorganic solutions above $2 \% \mathrm{w} / \mathrm{w}$ are independent of matrix composition. Current MWTN shows higher sensitivity and lower limits of detection (up to 12 times for acid solutions) than a conventional pneumatic nebulizer. The performance of the new prototype has been evaluated analyzing a certified bovine liver (CRM 185 R) and a spirit sample. Experimental results indicate that MWTN can be employed successfully for routine sample analysis.

\section{Introduction}

Analytical performance of plasma based spectrochemical techniques (ICP-AES and ICP-MS) strongly depends on the sample introduction system employed (i.e. nebulizer, spray chamber). ${ }^{1}$ The ideal nebulizer for spectrochemical techniques must fulfil the following requirements: (i) generate a fine and monodisperse aerosol with uniform velocity; (ii) nebulize solutions of different nature without modifying the aerosol characteristics; (iii) low sample consumption; and (iv) be easy to handle, robust and low-cost. The most employed nebulizers are the concentric pneumatic (PN) ones mainly due to its good performance and robustness. In these nebulizers, the aerosol is generated by the interaction between a high-velocity gas stream and the liquid bulk sample. In spite of its high acceptance in the analytical laboratories, concentric pneumatic nebulizers (PN) afford low analyte transport rate (and hence sensitivity) and are prone to getting blocked when dealing with solutions with high salt contents. For this reason, alternative nebulizer designs based on different principles for

Departamento de Química Analítica, Nutrición y Bromatología, Universidad de Alicante, P.O. Box 99, 03080 Alicante, Spain.

E-mail: guillermo.grindlay@ua.es the aerosol generation have been developed (e.g. thermal or ultrasonic nebulizers). ${ }^{2-5}$

The thermal nebulizer or thermospray (TN) consists of a narrow stainless steel capillary which is heated above the boiling point of the solvent. ${ }^{2}$ The aerosol is generated by the interaction between the liquid stream and the gas generated by the vaporization of a solvent fraction. The TN has been considered pneumatic in nature, since nebulization takes place by the interaction of a liquid and gas stream. Operating with the thermospray, a careful optimization of experimental parameters must be performed for improving limits of detection (LOD), since the aerosol characteristics depend, in a complex way, on these conditions (i.e. matrix nature, heating temperature, sample uptake rate, capillary internal diameter). ${ }^{6}$

The TN generates finer aerosols than a typical concentric pneumatic nebulizer improving the analyte and solvent transport rates to the plasma. ${ }^{7}$ Due to this reason, a desolvation system unit to reduce or overcome interferences is required. ${ }^{8}$ Coupling the TN to a desolvation system reduces limits of detection (LODs) one order of magnitude in respect to those obtained with a PN. ${ }^{9,10}$ Among drawbacks shown by TN it can be noted: (i) corrosion of the capillary when working with acidic solutions (a very common matrix in elemental analysis). 
Sometimes, a fused silica capillary has been inserted into the stainless steel capillary to avoid corrosion, improving chemical inertness and providing lower background signals. However, silica capillary heating is less efficient, making vaporization control more difficult; ${ }^{10,11}$ (ii) handling solutions with a high concentration of total dissolved solids is not recommended; and (iii) poor short and long-term stability.

The last energy sources evaluated with a $\mathrm{TN}$ has been the microwave radiation (MW). MW has been mainly applied in atomic spectrometry for sample preparation ${ }^{12}$ or plasma generation. ${ }^{13}$ Nonetheless, from 10 years on, it has also been successfully used as an alternative energy source for sample introduction purposes, such as desolvation ${ }^{14-18}$ and thermal nebulization (MWTN). ${ }^{19-21}$ Although MWTN and $\mathrm{TN}$ operate in a similar way, both systems show several differences in the sample heating process and hardware. Using a conventional $\mathrm{TN}$, the sample is heated through capillary walls by means of a conductive-convective mechanism. However, using the MWTN the sample is heated directly by the interaction between MW radiation and solvent molecule dipoles or ions. As a consequence of the differences in the heating mechanism, the MWTN design shows several modifications as compared with the standard TN. Firstly, the stainless steel capillary must be replaced with a PTFE one, since a microwave transparent material is mandatory. Secondly, the capillary is placed inside of a MW cavity where it interacts with the MW radiation produced by a magnetron. Finally, due to the need of using capillaries with a larger internal diameter, a silica restriction (i.e. a nozzle) placed at the end of PTFE capillary is needed, in order to improve vapour and liquid interaction.

The sample, as it happens with $\mathrm{TN}$, must be pumped by means of an HPLC pump. Nevertheless, conventional stainless-steel head pumps are inadequate to operate with the acidic or high salts content solutions usually employed when using the MWTN. For this reason, Bordera et al. ${ }^{19,20}$ introduced the sample by means of an injection valve and a large loop $(12 \mathrm{~mL}$ ) placed between the HPLC pump and the MW cavity. However, this approach does not afford continuous signals and requires the need to refill the loop periodically. As an alternative, peristaltic pumps have also been evaluated for sample pumping. ${ }^{21}$ The results obtained indicate that nebulization is possible, but the aerosol generation process becomes instable.

Two different MWTN designs, based on the use of different microwave cavities, have been reported in the literature. The first one employs a domestic multimodal cavity, ${ }^{20}$ whereas the second one uses a focalized cavity. ${ }^{19,21}$ The use of focalized cavities allows a better coupling between liquid sample and the MW radiation, giving rise to a more efficient heating process. The multimodal cavities employed do not afford a homogeneous MW field distribution and show several drawbacks: (i) the magnetron must be kept at its maximum nominal power since, otherwise, MW generation becomes irreproducible; (ii) a dummy load, placed inside the cavity, must be used for avoiding magnetron damage due to reflected radiation, so that most of the MW radiation available for aerosol generation is wasted by heating the dummy load. Liang et al. evaluated different focalized cavity designs. ${ }^{22}$ Among them, the so called $\mathrm{TM}_{010}$ affords adequate control of the heating processes and, hence, a reproducible aerosol generation. Using a $\mathrm{TM}_{010}$ cavity, these authors show that it is possible to generate aerosols using only 60 watts power. ${ }^{21}$

MWTN behaviour is affected by the same variables as conventional thermospray (i.e. matrix, sample uptake rate, MW power, and capillary and nozzle dimensions). However, when using MWTN, the dielectric properties of the solution also play a significant role since they determine the sample efficiency in transforming MW radiation into heat.

MWTN generates finer aerosols than a PN. ${ }^{19}$ Thus, for instance, the median of the volume drop size distribution $\left(D_{50}\right)$ for a $1.6 \%$ nitric acid solution at an uptake sample rate of $2 \mathrm{~mL} \mathrm{~min}^{-1}$ is $0.88 \mu \mathrm{m}$ and $5.48 \mu \mathrm{m}$ for a MWTN and a PN, respectively. Similar results can be obtained when using pure alcoholic solutions. As a rule, the reduction of the aerosol drop size distribution increases the analyte transport rate and hence sensitivity in ICP. However, as it usually happens with a conventional $\mathrm{TN}$, a desolvation unit is advisable to avoid plasma cooling. When the MWTN is coupled to a two step desolvation system, the sensitivity increases up to 10 times compared with a concentric pneumatic nebulizer. ${ }^{21}$ In spite of this signal improvement, the MW device shows similar LODs to a PN, due to the higher background and blank RSD values shown by the former. ${ }^{20,21}$

MWTN designs reported in literature have shown several drawbacks: (i) lack of robustness; (ii) poor, long and shortterm reproducibility; (iii) poor heating efficiency; and (iv) high matrix effects. ${ }^{19-21}$ All of these factors have made it impossible to apply this type of nebulizer for routine sample analysis. The main drawbacks shown by previous MWTN prototypes arise from an inefficient sample heating control due to the characteristics of the cavity, the MW generator, the pumping system and the nozzle. Therefore, it is expected that an improvement of the analytical figures of merit can be performed by redefining all these components. The goal of this work is to design and evaluate an improved microwave-based thermal nebulizer for liquid sample introduction in inductively coupled plasma atomic emission spectrometry. To this end, all the nebulizer components (i.e. MW cavity, nozzle) have been re-designed and the experimental variables optimized in order to get the better analytical response. The performance of the new prototype has been validated using samples of different natures.

\section{Experimental}

\section{MWTN design}

Fig. 1 and Table 1 show the experimental setup and the main characteristics of the new MWTN design. Table 1 also includes the characteristics of previous MWTN prototypes. As is shown in Fig. 1, the sample is introduced by an HPLC pump (Model 1500, Chrom Tech, Apple Valley, Minessota, USA) (1) through a PTFE capillary loop (2) placed at the centre of a $\mathrm{TM}_{010}$ cavity (3). The cavity has a cylindrical adjustable insertion (tuning screw) (4) for maintaining the resonance frequency at (or near) the nominal magnetron resonance frequency. ${ }^{17}$ A PEEK-SIL ${ }^{\circledR}$ nozzle (5) placed at the end of 


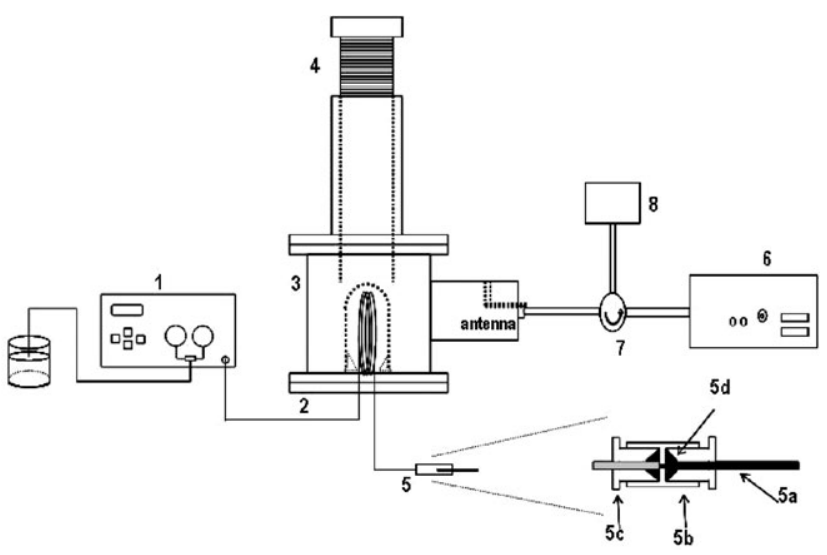

Fig. 1 Experimental setup of the MWTN. (1) HPLC pump; (2) PTFE capillary; (3) $\mathrm{TM}_{010}$ cavity; (4) tuning screw; (5) nebulizer nozzle, (5a) PEEK-SIL capillary; (5b) PEEK adapter; (5c) PEEK nut; (5d) Tefzel ${ }^{\circledR}$ ferrules; (6) magnetron; (7) circulator; (8) dummy load.

the PTFE capillary improves the interaction between the remaining liquid and the vapour generated inside the capillary by the action of the MW energy. Microwaves are generated by means of a magnetron of $2.45 \mathrm{GHz}$ (6) with a maximum power of $300 \mathrm{~W}$ (Model GMP $03 \mathrm{~K} / \mathrm{SM}$, Sairem SA, Neyron, France) connected to the cavity by a coaxial line. The MW generator is equipped with a safety device for protection against reflected radiation inside the cavity. This device consists of a circulator (7) and a dummy load (8).

The $\mathrm{TM}_{010}$ cavity employed was previously designed for liquid aerosol heating purposes, so that their dimensions were calculated for obtaining a maximum microwave field in the volume occupied by a cylindrical spray chamber placed at the cavity axis. ${ }^{17}$ For this reason, the PTFE capillary of the nebulizer must be placed vertically at the centre of the cylindrical chamber. The magnetron used allows precise microwave power control, since the supplied power can be smoothly modified in steps of $1 \mathrm{~W}$ and the reflected power measured by a power-meter.

Up to now, the nozzles employed in previous designs frequently showed problems of leakage, making necessary a skilled operator for the replacing of nozzles with different internal diameter. This drawback, together with those arising from the sample pumping, caused poor reproducibility and similar LODs than those with a pneumatic nebulizer. An ideal nozzle for the MWTN should fulfill the following requirements: (i) low dead volume; (ii) withstand corrosive solutions, high temperatures and pressures without deterioration; (iii) handle high solid contents solutions without clogging; and (iv) low thermal conductivity to keep sample evaporate from being condense. The new nozzle design presented in this work fulfils all the requirements above mentioned and has been fully made with commercially available components (Upchurch, Oak Harbor, Washington, USA). The nozzle restriction (5 in Fig. 1) consists of a $5 \mathrm{~cm}$ PEEK-SIL ${ }^{\circledR}$ tube (5a) (i.e. quartz capillary coated with PEEK polymer) (ref: 615005, 62005 and 63005), which can be easily coupled to a PEEK adapter (5b) (ref: 702), by means of PEEK nuts (5c) (ref: P-235) and Tefzel ${ }^{\mathbb{R}}$ ferrules (5d) (ref: P-200). The PTFE capillary at the exit of the $\mathrm{TM}_{010}$ cavity is also coupled to the PEEK adapter by means of PEEK nuts and Tefzel ${ }^{\circledR}$ ferrules. This way, the dead volume inside the nozzle is negligible, leakage is eliminated and all components can be replaced in just a few seconds without any tools.

A peristaltic pump and an HPLC pump have been tested for sample introduction with the MWTN design. Peristaltic pumps are less expensive and easier to handle than HPLC pumps. It has been observed that the peristaltic pump was not able to provide a reproducible sample uptake rate as the system pressure increases ( $>50 \mathrm{psi}$ ), as a consequence of the sample vaporization by MW heating. The HPLC pump employed in this work was designed to handle all kinds of concentrated inorganic matrices (i.e. acids and salts), since all pump components in contact with the sample are made of PEEK instead of stainless-steel. For this reason, an injection valve is unnecessary and a stationary signal is obtained. The pump also incorporates a self-flush system for cleaning the pistons from any possible matrix deposit. The pressure inside the PTFE capillary can be easily monitored and employed as a nebulizer performance control.

Table 1 compares the characteristics of previous and current MWTN designs. The first MWTN prototype (\#1) employed a focalized cavity from a commercial MW digestor. ${ }^{19}$ Although

Table 1 Characteristics of the previous and current MWTN designs

\begin{tabular}{|c|c|c|c|c|}
\hline \multirow[b]{2}{*}{ Characteristics } & \multicolumn{4}{|c|}{ MWTN design } \\
\hline & \#1 (ref. 19) & \#2 (ref. 20) & \#3 (ref. 21) & Current \\
\hline Cavity & Focalized & Multimodal & Focalized & Focalized \\
\hline MW power/W & 300 & 800 & 300 & 300 \\
\hline Power control & Yes & No & Unknown & Yes \\
\hline Pumping system & HPLC pump & HPLC pump & Peristaltic pump & HPLC pump \\
\hline$Q_{1} / \mathrm{mL} \mathrm{min}^{-1}$ & $>1.5$ & $>1.0$ & $>0.5$ & $>0.8^{a} />0.5^{b}$ \\
\hline Matrix & Inorganic & Inorganic/organic & Inorganic & Inorganic/organic \\
\hline \multicolumn{5}{|l|}{ Minimum concentration $(\%)$} \\
\hline Inorganic matrices & $>4.5$ & $>0.8$ & $>3.0$ & $>0.25$ \\
\hline Organic matrices & $100^{c}$ & 100 & - & $>40$ \\
\hline Nozzle i.d. $\left(d_{\mathrm{N}}\right) / \mu \mathrm{m}$ & $75-100$ & $75-100$ & 75 & $150-300$ \\
\hline PTFE capillary length $\left(l_{\mathrm{C}}\right) / \mathrm{cm}$ & $20-30$ & 1800 & 30 & $50-150$ \\
\hline PTFE capillary i.d. $\left(d_{\mathrm{C}}\right) / \mu \mathrm{m}$ & 500 & 500 & 500 & $300-800$ \\
\hline Nozzle robustness/sample leaks & Poor/yes & Poor/yes & Poor/yes & High/no \\
\hline
\end{tabular}


this type of cavities allows a good interaction between sample and microwave radiation, the results obtained were poor, since the MW irradiation zone was too narrow (i.e. $1 \mathrm{~cm}$ ). For this reason, a high sample uptake rate $\left(>1.5 \mathrm{~mL} \mathrm{~min}^{-1}\right)$ and acid matrix concentration $(>5 \%)$ were required to generate a useful aerosol for ICP-AES purposes. Softer nebulization conditions (i.e. lower $Q_{1}$ and matrix concentration) were achieved using the multimodal cavity from a domestic oven with a more powerful MW generator (\#2). ${ }^{20}$ However, sample heating was irreproducible since it was necessary to introduce a water dummy load inside the cavity to protect the magnetron from reflected radiation. Ding et al. ${ }^{21}$ reported an improved MWTN design using a focalized $\mathrm{TM}_{010}$ cavity (\#3). Nevertheless, the lack of robustness of the pumping system (a peristaltic pump) and the nebulizer nozzle caused the analytical figures of merit not to be better than those obtained with a conventional pneumatic concentric nebulizer. The MWTN presented in this work has been designed for improving, simultaneously, both the system robustness and heating efficiency. When using this new MWTN it is possible to nebulize $0.25 \% \mathrm{w} / \mathrm{w}$ inorganic solutions (concentrations ten times lower than those required by previous prototypes) using capillaries and nozzles of larger internal diameters. As regards organic solutions, the current design can nebulize continuously alcoholic solutions above $40 \% \mathrm{w} / \mathrm{w}$, whereas previous prototypes were only able to nebulize pure alcoholic solutions. It is important to note that unlike previous prototypes, matrix concentration and sample uptake rate employed with current MWTN are close to standard experimental conditions usually employed for routine sample analysis.

The MWTN was coupled to a home-made thermostated cyclonic spray chamber (inner volume $33 \mathrm{~cm}^{3}$ ) for ICP-AES measurements. Aerosol carrier gas flow was introduced inside the spray chamber by means of a $\mathrm{T}$-joint placed at the nebulizer entrance and was controlled by means of a rotameter (Cole-Palmer Ins. Co., Chicago, Illinois, USA). The spray chamber was cooled at $-5{ }^{\circ} \mathrm{C}$ using a thermostated bath (Haake F3-K, Haake Mess-Technik GmBH. U. Co., Karlsruhe, Germany) to avoid plasma cooling. When nebulizing organic samples, an extra desolvation step made up of a homemade Peltier ${ }^{23}$ cooler $(30 \mathrm{~cm}$ length and $8 \mathrm{~mm}$ internal diameter) at $-30{ }^{\circ} \mathrm{C}$ was employed.

For the sake of comparison, a concentric pneumatic nebulizer (Model TR-30-K2, Meinhard, Santa Ana, California, USA) coupled to the previously described cyclone spray chamber was used. Due to the low backpressure of concentric pneumatic nebulizers, a peristaltic pump (Model Minipulse 3, Gilson, Villiers-Le-Bel, France) and Tygon tubes (SC0007, Ismatec SA, Labortechnik-Analytik, Glattbrugg, Switzerland) were used to deliver the sample. Nebulizer gas flow and spray chamber temperature were controlled by the same rotameter and thermostated bath employed with the MWTN.

\section{Reagents and samples}

All chemicals employed were of analytical grade (Merck, Darmstadt, Germany). Test solutions containing $10 \mu \mathrm{g} \mathrm{mL}^{-1}$ were prepared by diluting appropriate aliquots of $1000 \mu \mathrm{g} \mathrm{mL}^{-1}$ reference solutions in the appropriate solvent (diluted solutions of nitric and hydrochloric acid, sodium chloride, methanol, ethanol and propan-2-ol) for ICP-AES measurements. The concentration range spanned from 0.25 to $2 \% \mathrm{w} / \mathrm{w}$ for inorganic matrices and from 40 to $100 \%$ $\mathrm{w} / \mathrm{w}$ for organic matrices. Solutions used to measure analyte transport rates were prepared from $\mathrm{MnCl}_{2} \cdot 4 \mathrm{H}_{2} \mathrm{O}$. A certified bovine liver (CRM $185 \mathrm{R}, \mathrm{BCR}$, Geel, Belgium) and a spirit sample (A'Espenuca, Betanzos, A Coruña) were analyzed to validate the behaviour of the MWTN. The bovine sample was previously digested by means of a MW oven (MSP 1000, CEM, Matthews, North Carolina, USA) using the program recommended by the manufacturer, ${ }^{24}$ whereas the spirit was analyzed directly, without any sample pre-treatment. In both cases, samples were spiked with $10 \mu \mathrm{g} \mathrm{mL}^{-1}$ of several elements prepared from a multielemental standard ICP-IV (Merck, Darmstadt, Germany) to perform a recovery test of those elements that were not present in the sample and $10 \mu \mathrm{g} \mathrm{mL}^{-1} \mathrm{Sc}$ prepared from the monoelemental reference Sc solution. This element was used as an internal standard.

\section{ICP instrumentation}

ICP-AES measurements were performed using a Perkin Elmer Optima 3000 ICP-AES instrument (PerkinElmer, Uberlingen, Germany). Table 2 gathers the operating conditions employed. Analytical lines were selected so as to cover a wide range of line energies within 1.85 to 15.96 (Table 3).

Limits of detection (LODs) were calculated according to the approach described by Boumans: ${ }^{25}$

$$
\mathrm{LOD}=3\left(\mathrm{RSD}_{\mathrm{B}}\right) \frac{C_{0}}{\mathrm{SBR}}
$$

where $\left(\mathrm{RSD}_{\mathrm{B}}\right)$ is the relative standard deviation obtained from twenty replicates of the blank; $C_{0}$ is the analyte concentration of the solution measured (i.e. $10 \mu \mathrm{g} \mathrm{mL}^{-1}$ ); and SBR is the signal to background ratio.

\section{Aerosol drop size distribution measurements}

Aerosol drop size distributions (DSD) were measured by means of a laser Fraunhofer diffraction system (Model 2600c, Malvern Instruments Ltd, Malvern, Worcestershire, UK). All measurements were made at $1 \mathrm{~mm}$ from the nebulizer

Table 2 Operating ICP-AES conditions

Perkin-Elmer Optima 3000 ICP-AES

\begin{tabular}{ll}
\hline Plasma forward power/W & 1450 \\
Argon flow rate $/ \mathrm{L} \mathrm{min}^{-1}$ : & 16 \\
Plasma & $0.7^{a}-1.5^{b}$ \\
Auxiliary & $0.6^{c}-0.5^{d}$ \\
Nebulizer & Variable \\
Sample uptake rate $/ \mathrm{mL} \mathrm{min}{ }^{-1}$ & $12^{a}-10^{d}$ \\
Observation height $/ \mathrm{mm} \mathrm{ALC}$ & 0.8 \\
Injector inner tube diameter $/ \mathrm{mm}$ & 100 \\
Integration time $/ \mathrm{ms}$ & $10 / 3$ \\
Readings/replicates & \\
${ }^{a}$ Inorganic matrix. ${ }^{b}$ Organic matrix. ${ }^{c} \mathrm{PN} .{ }^{d} \mathrm{MWTN}$. & \\
\hline
\end{tabular}


Table 3 Elements, wavelengths and energy values for the selected lines tested

\begin{tabular}{|c|c|c|}
\hline Element & Wavelength/nm & $E_{\text {sum }} / \mathrm{eV}$ \\
\hline Li I & 670.781 & 1.85 \\
\hline Sr I & 460.673 & 2.69 \\
\hline $\mathrm{Ca} \mathrm{I}$ & 422.673 & 2.93 \\
\hline $\mathrm{Al}$ I & 396.152 & 3.14 \\
\hline $\mathrm{Cr}_{\mathrm{I}}$ & 357.869 & 3.46 \\
\hline Ag I & 328.068 & 3.78 \\
\hline $\mathrm{Cu} \mathrm{I}$ & 324.754 & 3.82 \\
\hline $\mathrm{Al} \mathrm{I}_{\mathrm{C}}$ & 309.271 & 4.02 \\
\hline $\mathrm{Mg}_{\mathrm{I}}$ & 285.213 & 4.35 \\
\hline $\mathrm{Ni} I$ & 232.003 & 5.34 \\
\hline $\mathrm{Cd}_{\mathrm{I}}$ & 361.061 & 7.38 \\
\hline $\mathrm{Ba} \mathrm{I}$ & 455.403 & 7.93 \\
\hline $\mathrm{Sr}$ II & 421.552 & 8.64 \\
\hline $\mathrm{Sr}$ II & 407.771 & 8.73 \\
\hline Ba II & 233.527 & 11.22 \\
\hline Mg II & 280.270 & 12.07 \\
\hline Mn II & 257.610 & 12.29 \\
\hline $\mathrm{Cr}$ II & 267.710 & 12.92 \\
\hline $\mathrm{Fe}$ II & 238.204 & 13.07 \\
\hline $\mathrm{Ca}$ II & 317.933 & 13.16 \\
\hline Co II & 238.892 & 13.46 \\
\hline Co II & 228.616 & 13.70 \\
\hline Ni II & 231.064 & 14.03 \\
\hline $\mathrm{Cd}_{\mathrm{II}}$ & 214.438 & 14.77 \\
\hline $\mathrm{Pb}$ II & 220.353 & 14.79 \\
\hline Zn II & 202.548 & 15.51 \\
\hline $\mathrm{Cu}$ II & 224.700 & 15.96 \\
\hline
\end{tabular}

tip. A lens with a focal length of $63 \mathrm{~mm}$, which enables the system to measure droplets with diameters between 1.2 and $118 \mu \mathrm{m}$, was used. Calculations were performed by means of software version B.0D which transforms the energy distribution into aerosol drop size distribution using a model-independent algorithm that does not preclude any particular distribution function. A set of five replicates was performed in each case, the precision of these measurements always lower than $4 \%$.

\section{Analyte transport measurements}

Analyte transport rate $\left(W_{\text {tot }}\right)$ measurements were performed by nebulizing a solution of $200 \mu \mathrm{g} \mathrm{mL}^{-1} \mathrm{Mn}$ during a given period of time and trapping the aerosol at the exit of the spray chamber with a glass fiber filter (type A/E, $47 \mathrm{~mm}$ diameter, $0.3 \mu \mathrm{m}$ pore size, Gelman Sciences, Ann Arbor, MI, USA). The filter was then washed out into a volumetric flask with $1.0 \% \mathrm{w} / \mathrm{w}$ nitric acid and the Mn concentration measured by flame atomic absorption spectrometry. A set of three replicates was performed in each case, the RSD of these measurements always lower than $5 \%$.

\section{Results and discussion}

\section{Effect of the incident microwave power}

Fig. 2 shows the effect of the nominal incident MW power on the $\mathrm{Mn}$ net emission intensity in ICP-AES obtained with different nitric acid solutions. Reflected MW power inside the cavity has been $50 \pm 5 \mathrm{~W}$ irrespective of the experimental conditions employed. Results shown in Fig. 2 indicate that for all nitric acid solutions, the Mn net emission intensity increases

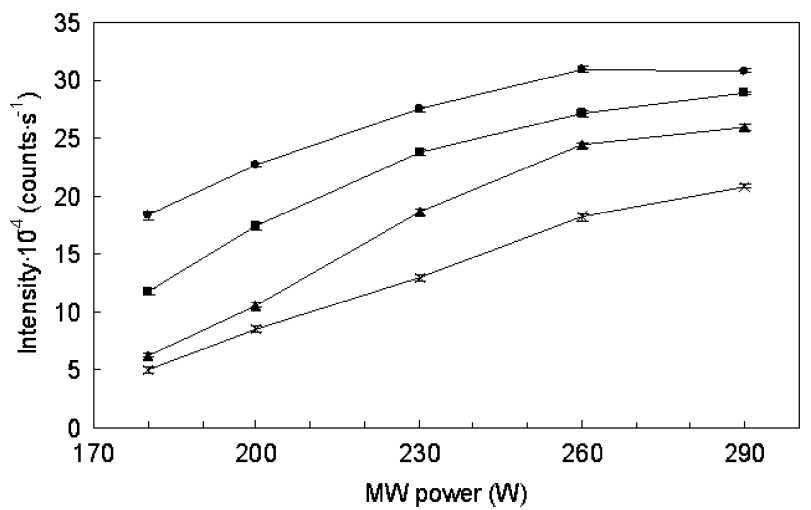

Fig. 2 Effect of nominal incident microwave power on the Mn net emission intensity for different nitric acid concentrations. (O) $2 \%$ $\mathrm{w} / \mathrm{w} ;(\boldsymbol{\square}) 1 \% \mathrm{w} / \mathrm{w} ;(\boldsymbol{\Delta}) 0.5 \% \mathrm{w} / \mathrm{w} ;(\times) 0.25 \% \mathrm{w} / \mathrm{w} . Q_{1} 1.8 \mathrm{~mL} \mathrm{~min}^{-1}$; $d_{\mathrm{N}} 200 \mu \mathrm{m} ; l_{\mathrm{C}} 1 \mathrm{~m} ; d_{\mathrm{C}} 500 \mu \mathrm{m}$.

as the MW power is increased up to $260 \mathrm{~W}$. For inorganic matrices above $0.5 \% \mathrm{w} / \mathrm{w}$, a further increase in the $\mathrm{MW}$ power does not cause a noticeable increase in the emission signal. However, when MW power is raised up to $290 \mathrm{~W}$, the $0.25 \%$ $\mathrm{w} / \mathrm{w}$ nitric acid solution shows an additional signal enhancement of $25 \%$.

In order to explain this behaviour, it must be considered that the ICP emission signal depends mainly on the characteristics of the aerosols generated by the nebulizer and on the spray chamber design. ${ }^{1,26}$ Finer aerosols improve solution (i.e. analyte and solvent) transport to the plasma, and hence the emission signal. Nonetheless, excessive solvent (or matrix) loading can deteriorate excitation conditions, giving rise to a decrease in the emission intensity. ${ }^{27} W_{\text {tot }}$ can be used to evaluate the analyte transport rate, and $\mathrm{Mg}$ ratio $^{28,29}$ or $\mathrm{Ar}$ intensity to measure the plasma excitation conditions. ${ }^{30,31}$ Results indicate that there is no influence of MW power on $\mathrm{Mg}$ ratio and Ar intensity for all conditions studied in Fig. 2. Therefore, the behaviour shown in Fig. 2 is likely to be related to aerosol characteristics.

When the incident microwave power is increased, more energy can be absorbed by the sample leading to a better heating process. Therefore, the amount of solvent evaporated in the capillary increases and higher energy is available to generate the aerosol (i.e. higher pressure inside the capillary). The higher pressure provided by the HPLC pump evidences this fact. As a consequence, primary aerosols become finer as MW power is increased. In fact, when MW power increases from 180 to $290 \mathrm{~W}$ for $1 \% \mathrm{w} / \mathrm{W}$ nitric acid solution, pressure raises by $90 \%$, whereas $D_{50}$ (i.e., the median of the volume drop size distribution) decreases from $26.42 \mu \mathrm{m}$ to $12.89 \mu \mathrm{m}$. Lower DSD means increased analyte transport rate to the plasma. Table 4 shows the $W_{\text {tot }}$ values obtained for different matrices and experimental conditions. As it can be observed in this Table, for nitric acid solutions, when increasing MW power, higher $W_{\text {tot }}$ values are obtained. On comparing the results shown in Fig. 2 and Table 4, it can be derived that $W_{\text {tot }}$ and intensity values are correlated. Thus, for instance, when MW power is increased from $180 \mathrm{~W}$ to $290 \mathrm{~W}$ for a $2 \% \mathrm{w} / \mathrm{w}$ acid nitric solution, both $W_{\text {tot }}$ and emission signals increase 1.9 times. 
Table 4 Analye transport rate for inorganic matrices using different microwave powers and sample uptake rates with MWTN. $d_{\mathrm{N}} 200 \mu \mathrm{m}$; $l_{\mathrm{C}} 1 \mathrm{~m} ; d_{\mathrm{C}} 500 \mu \mathrm{m}$

\begin{tabular}{lllll}
\hline Matrix & $\begin{array}{l}\text { Concentration } \\
(\% \text { w/w })\end{array}$ & $P_{\text {Mw }} / \mathrm{W}$ & $\begin{array}{l}Q_{1} / \\
\mathrm{mL} \mathrm{min}\end{array}$ & $\begin{array}{l}W_{\text {tot }} / \\
\mu \mathrm{g} \mathrm{min}\end{array}$ \\
\hline $\mathrm{HNO}_{3}$ & 0.25 & 180 & 1.8 & 1.4 \\
$\mathrm{HNO}_{3}$ & 2.00 & 180 & 1.8 & 3.5 \\
$\mathrm{HNO}_{3}$ & 0.25 & 290 & 1.8 & 3.6 \\
$\mathrm{HNO}_{3}$ & 2.00 & 290 & 1.8 & 6.7 \\
$\mathrm{HCl}$ & 0.25 & 290 & 1.8 & 3.3 \\
$\mathrm{HCl}$ & 2.00 & 290 & 1.8 & 6.5 \\
$\mathrm{NaCl}$ & 0.25 & 290 & 1.8 & 2.6 \\
$\mathrm{NaCl}$ & 2.00 & 290 & 1.8 & 5.7 \\
$\mathrm{HNO}_{3}$ & 0.25 & 290 & 0.9 & 0.8 \\
$\mathrm{HNO}_{3}$ & 2.00 & 290 & 0.9 & 2.1 \\
\hline
\end{tabular}

\section{Effect of matrix}

Fig. 2 shows that the emission signal also depends on the matrix. The higher the nitric acid concentration, the higher the signal obtained. In addition, it can also be observed that signal enhancement is more significant at low MW power values. Thus, when nitric acid concentrations rise from 0.25 to $2 \%$ $\mathrm{w} / \mathrm{w}$ at $180 \mathrm{~W}$, the signal is enhanced 3.7 times, whereas at $290 \mathrm{~W}$ the enhancement factor is only of 1.5 times.

This behaviour can be explained by taking in mind that, when using the MWTN, the aerosol generation process depends on the sample's physical properties. The effectiveness of the sample solution in transforming MW radiation into heat is usually evaluated by means of the loss factor $(\tan \delta)$. Once the sample is heated and partially vaporized, other sample properties such as expansion factor (i.e., the gas volume produced by the vaporization of a single mass unit of solvent at a given boiling temperature), ${ }^{32}$ surface tension and viscosity determine the characteristics of the aerosols generated with a thermalbased nebulizer.

Inorganic solutions are mainly heated by ionic conductance, since ions migrate under the influence of the electrical field and produce heat following the Joule effect. The higher the ionic concentration (i.e. higher $\tan \delta$ ) the higher the amount of heat released,$^{33}$ and then, the greater amount of sample evaporated inside the PTFE capillary. As a consequence, finer aerosols are generated. Thus, for instance, $D_{50}$ decreases from 21 to $12 \mu \mathrm{m}$ when nitric acid ionic concentration is increased from $0.25 \%$ to $2 \% \mathrm{w} / \mathrm{w}$. In addition, due to this drop size reduction, more analyte can be transported to the plasma (see Table 4), increasing the analytical signal (Fig. 2).

As it has been pointed out previously, emission signal is more influenced by matrix concentration at low MW powers. This fact can be explained taking into account that when MW power is increased, more heat can be produced independent of sample dielectric properties (i.e. $\tan \delta$ ).

Table 5 shows $\mathrm{Mn}$ net intensity for different inorganic matrices i.e. hydrochloric acid and sodium chloride. As it has been shown previously with nitric acid (Fig. 2), when hydrochloric acid and sodium chloride concentration is increased, a higher signal is obtained. The signal values obtained for hydrochloric acid solutions are very similar to those shown for nitric acid (Fig. 2). However, sodium chloride solutions provide lower emission intensity values than acid solutions for
Table 5 Effect of matrix concentration on Mn net signal intensity for different inorganic and organic matrices. Inorganic solutions: $P_{\mathrm{MW}}$ $290 \mathrm{~W} ; Q_{1} 1.8 \mathrm{~mL} \mathrm{~min}^{-1}$. Pure organic solutions: $P_{\mathrm{MW}} 100 \mathrm{~W} ; Q_{1} 1.4$

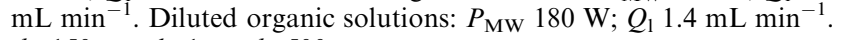
$d_{\mathrm{N}} 150 \mu \mathrm{m} ; l_{\mathrm{C}} 1 \mathrm{~m} ; d_{\mathrm{C}} 500 \mu \mathrm{m}$

\begin{tabular}{ll}
\hline Matrix & Intensity/counts s \\
\hline $\mathrm{HCl} 0.25 \%$ & 213000 \\
$\mathrm{HCl} 2.00 \%$ & 308000 \\
$\mathrm{NaCl} 0.25 \%$ & 171000 \\
$\mathrm{NaCl} 2.00 \%$ & 226000 \\
Methanol $100 \%$ & 151000 \\
Methanol $60 \%$ & 50000 \\
Ethanol $100 \%$ & 130000 \\
Ethanol $60 \%$ & 72000 \\
Propan-2-ol $100 \%$ & 75000 \\
Propan-2-ol $60 \%$ & 100000 \\
\hline
\end{tabular}

all the concentrations tested. Therefore, in this case, signal differences can be related to matrix effects on aerosol transport phenomena, since sodium chloride solutions show lower $W_{\text {tot }}$ values (Table 4). ${ }^{34}$ Thus, for instance, $W_{\text {tot }}$ values for $2 \% \mathrm{w} / \mathrm{w}$ nitric and hydrochloric acid solution are 6.7 and

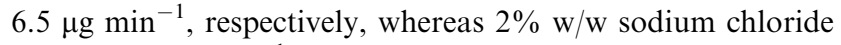
shows $5.7 \mu \mathrm{g} \mathrm{min}^{-1}$. For diluted solutions (i.e. matrix concentration lower $1 \% \mathrm{w} / \mathrm{w}$ ), small differences in ionic conductance can affect nebulization. Ions with higher specificic conductance values (e.g. $\mathrm{H}^{+}$) are able to absorb MW radiation more efficiently than others with lower specific conductance $\left(\right.$ e.g. $\left.\mathrm{Na}^{+}\right)$. As a consequence of lower sodium heating efficiency, coarser aerosols are generated with diluted saline solutions. Fig. 3 shows the volume drop size distribution curves plotted in an accumulated semi-logarithmic mode for several inorganic (Fig. 3A) and organic matrices (Fig. 3B). According to the plot of Fig. 3, the curves are shifted to the left as the aerosol becomes finer. As it can be seen in Fig. 3A, primary aerosol for inorganic acid solutions are similar and finer than for sodium chloride. Finer aerosol drop size distribution for inorganic acids improve aerosol transport and, hence, signal with regard to a salt solution. Other physical properties, such as expansion factor or surface tension, have no noticeable effect on aerosol generation for inorganic matrices, since they remain almost constant for all solutions tested.

The MWTN design evaluated in the present work shows a noticeable difference when compared with previous ones, since in this case, and for a given concentration, there is no significant effect of the acid nature on the signal (for all concentration and elements tested) ${ }^{19,21}$ This effect is a direct consequence of the improved MW heating capability afforded by the new design. Fig. 4 shows the effect of nitric acid concentration, covering a larger concentration range on $\mathrm{Mn}$ emission signal and on the $D_{50}$ of the primary DSD with the MWTN. Similar results are obtained employing hydrochloric acid or sodium chloride. When the matrix concentration is increased the $\mathrm{Mn}$ signal peaks at around $2 \% \mathrm{w} / \mathrm{w}$. At lowers concentrations, the signal is mainly related with the aerosol characteristics. Increasing concentration tends to reduce aerosol drop size distribution (i.e. lower $D_{50}$ ), thus improving the analyte transport to the plasma. However, at higher concentrations, the aerosol characteristics remain almost constant 

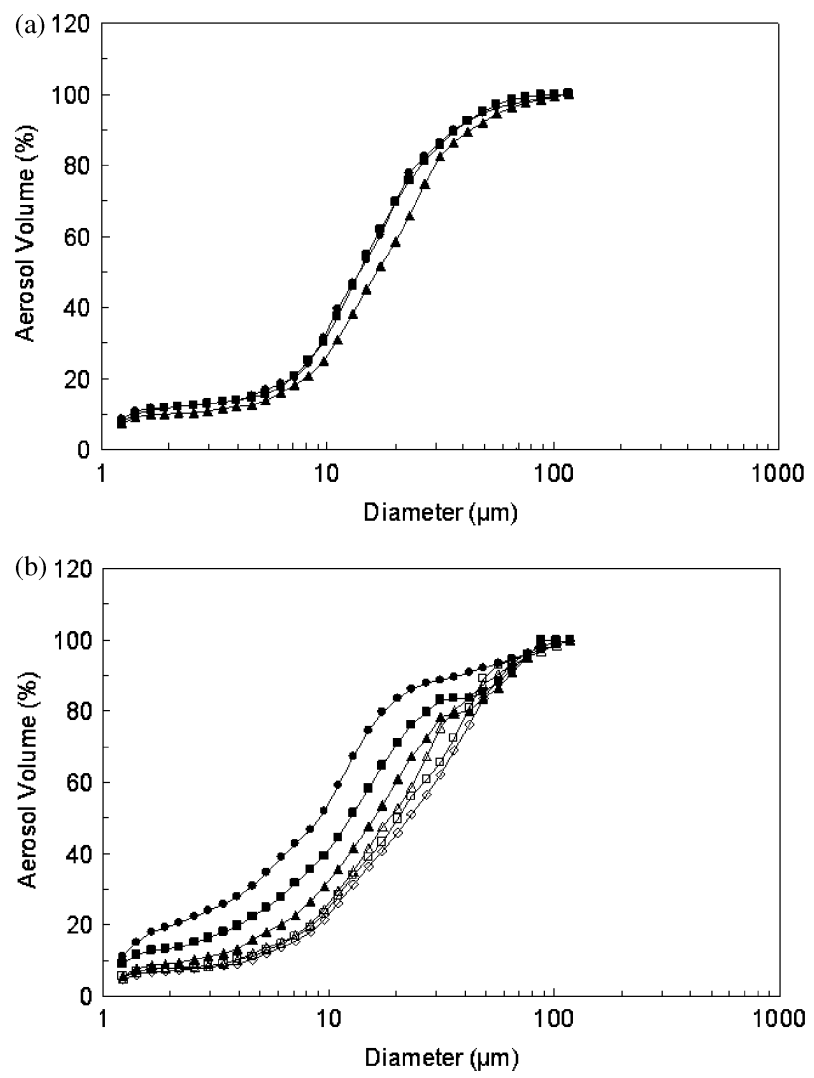

Fig. 3 Volume drop size distribution of the primary aerosol obtained for different matrices with the MWTN. (a) Inorganic matrices: (0) nitric acid $0.5 \% \mathrm{w} / \mathrm{w} ;(\boldsymbol{\square})$ hydrochloric acid $0.5 \% \mathrm{w} / \mathrm{w} ;(\boldsymbol{\Delta})$ sodium chloride $0.5 \% \mathrm{w} / \mathrm{w}$. (b) Organic matrices: (O) methanol 100\% w/w; (ם) ethanol 100\% w/w; $(\boldsymbol{\Delta})$ propan-2-ol 100\%w/w; ( $\bigcirc)$ methanol $60 \% \mathrm{w} / \mathrm{w} ;(\square)$ ethanol $60 \% \mathrm{w} / \mathrm{w} ;(\triangle)$ propan-2-ol $60 \% \mathrm{w} / \mathrm{w}$. Inorganic: $P_{\mathrm{MW}} 290 \mathrm{~W} ; Q_{1} 1.8 \mathrm{~mL} \min ^{-1} ; d_{\mathrm{N}} 150 \mu \mathrm{m} ; l_{\mathrm{C}} 1 \mathrm{~m}$; $d_{\mathrm{C}} 500 \mu \mathrm{m}$. Organic solutions: $P_{\mathrm{MW}} 290 \mathrm{~W} ; Q_{1} 1.4 \mathrm{~mL} \mathrm{~min}{ }^{-1}$; $d_{\mathrm{N}} 150 \mu \mathrm{m} ; l_{\mathrm{C}} 1 \mathrm{~m} ; d_{\mathrm{C}} 500 \mu \mathrm{m}$.

$\left(D_{50} \approx 12 \mu \mathrm{m}\right)$, whereas the signal can decrease up to $30 \%$. Several authors reported that a high acid concentration may affect analyte transport or reduce plasma atomization/excitation capabilities. ${ }^{35}$ Measurements at $5 \%$ and $2 \% \mathrm{w} / \mathrm{w}$ nitric acid solutions show that there is no significant difference between the $W_{\text {tot }}$ values obtained for both solutions. Nevertheless, Ar intensity for a $5 \% \mathrm{w} / \mathrm{w}$ nitric acid solution is about $30 \%$ lower than for a $2 \%$ one. From theses results, it can be concluded that signal reduction for nitric acid solutions above $2 \% \mathrm{w} / \mathrm{w}$ are related to plasma energetic conditions since DSD and $W_{\text {tot }}$ are not influenced by matrix concentration.

Table 5 also shows Mn net emission for pure and $60 \% \mathrm{w} / \mathrm{w}$ alcohol solutions (i.e. methanol, ethanol and propan-2-ol). With the exception of propan-2-ol, the higher the alcohol concentration the higher the signal obtained. When comparing pure alcoholic solutions, the Mn sensitivity follows the following order: methanol $>$ ethanol $>$ propan-2-ol. However, for $60 \% \mathrm{w} / \mathrm{w}$ solutions, the relative behaviour among alcohols is the opposite: methanol < ethanol < propan-2-ol. In order to explain these behaviours, it must be taken into account that aerosol generation with organic matrices shows some differences with respect to inorganic ones. In one hand, organics are

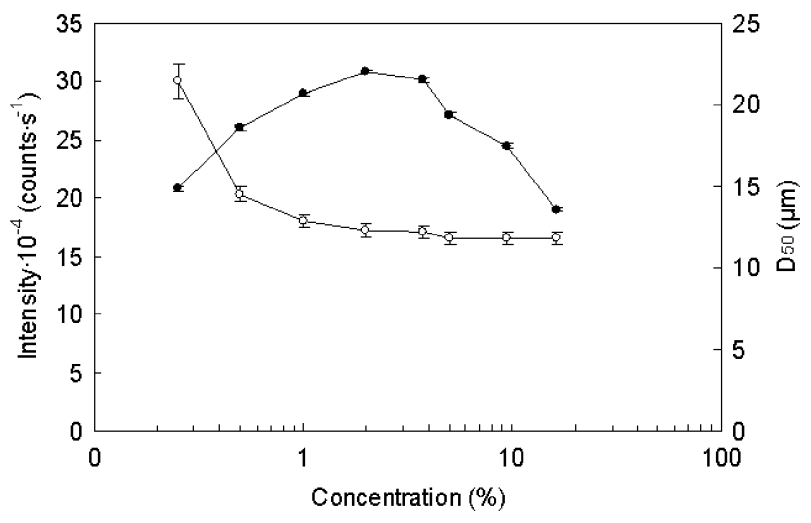

Fig. 4 Effect of nitric acid concentration on the Mn net emission intensity and on the median of the primary volume drop size distribu-

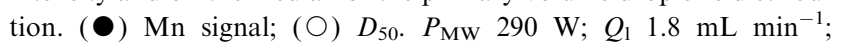
$d_{\mathrm{N}} 200 \mu \mathrm{m} ; l_{\mathrm{C}} 1 \mathrm{~m} ; d_{\mathrm{C}} 500 \mu \mathrm{m}$.

heated by dielectric polarization (i.e. dipole rotation motion) instead of ionic conductance. On the other hand, when nebulizing organic solutions, it is necessary to take into account that the ratio organic : water modifies both the MW heating efficiency and other important physical solution properties, such as expansion factor, surface tension, etc.

As it has been pointed out previously, thermal aerosol generation depends on the expansion factor. The higher the expansion factor, the higher the energy available for aerosol generation, and hence the finer the aerosols generated. ${ }^{2,32}$ For pure alcoholic solutions, methanol shows the highest expansion factor followed by ethanol and propan-2-ol. For this reason, methanol is expected to provide the finest aerosols. Fig. 3B shows primary aerosol volume drop size distribution curves for pure and diluted organic solutions. As it can be seen in this Figure that pure methanol solution affords finer aerosols than ethanol and propan-2-ol. So, higher $W_{\text {tot }}$ and signal must be expected for methanol (Table 5). As regards dielectric properties, it seems that they are not too critical as with inorganic matrices, since methanol is the alcohol with the lowest $\tan \delta .^{36}$

When the alcohol percentage is reduced the solution expansion factor increases whereas $\tan \delta$ decreases. From the experimental results, it seems that the increase for all the alcohols tested in the expansion factor does not fully counterbalance the reduction of the heating efficiency, thus giving rise to coarser aerosols (Fig. 3B), lower $W_{\text {tot }}$, and therefore a lower emission signal. In addition, the surface tension of diluted alcohol solutions is higher than for the undiluted ones, a higher amount of energy being necessary to generate the same liquid surface. Finally, changes in the viscosity (of the solutions) may also account for the differences found between undiluted and diluted alcohol. Higher viscosity helps to dampen instabilities of the liquid surface, more energy being necessary to generate new surfaces (i.e. coarser aerosols). When the alcohol content is reduced from $100 \%$ to $60 \%$ $\mathrm{w} / \mathrm{w}$, solution viscosity increases. The enhancement factor of the viscosity is more significant for methanol (2.71) than for ethanol (2.16) and propan-2-ol (1.5). ${ }^{37}$ Hence, coarser aerosols are expected for methanol solutions than for propan-2-ol 


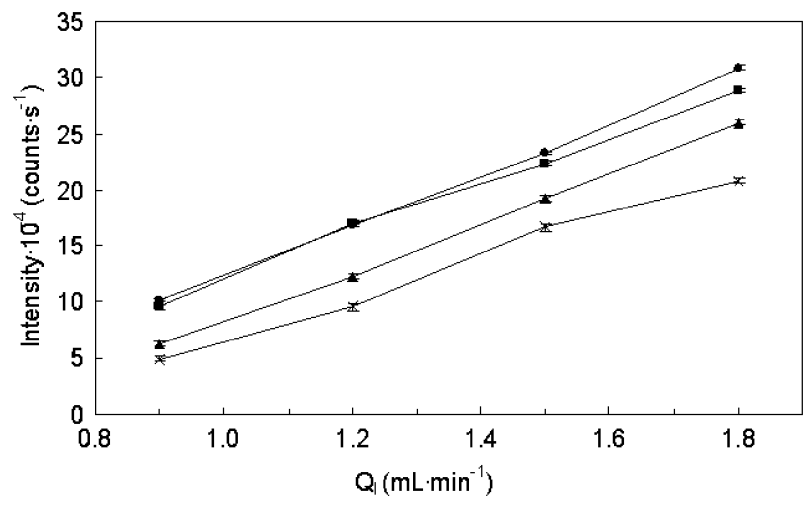

Fig. 5 Effect of sample uptake rate on the Mn net emission intensity for different nitric acid solutions $(\mathrm{w} / \mathrm{w})$. (O) $2 \% \mathrm{w} / \mathrm{w} ;(\boldsymbol{\square}) 1 \% \mathrm{w} / \mathrm{w}$; (A) $0.5 \% \mathrm{w} / \mathrm{w} ;(\times) 0.25 \% \mathrm{w} / \mathrm{w} . P_{\mathrm{MW}} 290 \mathrm{~W} ; d_{\mathrm{N}} 200 \mu \mathrm{m} ; l_{\mathrm{C}} 1 \mathrm{~m}$; $d_{\mathrm{C}} 500 \mu \mathrm{m}$.

solutions (Fig. 3B) and again, lower analyte transport and signals values.

\section{Effect of sample uptake rate}

Fig. 5 shows the effect of the sample uptake rate $\left(Q_{1}\right)$ on $\mathrm{Mn}$ net emission intensity in ICP-AES for different nitric acid solutions. As it can be observed in the Figure, an increase in $Q_{1}$ gives rise to higher intensity values for all the solutions tested. This is the typical behaviour shown by pneumatic and thermal nebulizers, and it is usually explained by taking into account that $W_{\text {tot }}$ increases as $Q_{1}$ is increased. Moreover, in thermal nebulization, increasing $Q_{1}$ causes the volume of the solution evaporated to increase (i.e. higher pressure inside the capillary), thus giving rise to an increase in the energy available for aerosol generation. Thus, for instance, pressure values for $2 \% \mathrm{w} / \mathrm{w}$ nitric acid solution

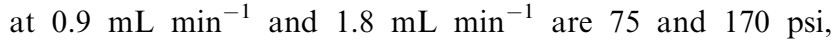
respectively, which in turn, causes $D_{50}$ to decrease from $21 \mu \mathrm{m}$ to $13 \mu \mathrm{m}$. Table 4 shows the $W_{\text {tot }}$ values obtained for different nitric acid solutions at liquid flow rates of 0.9 and $1.8 \mathrm{~mL} \mathrm{~min}{ }^{-1}$. As it can be observed, the signal improvements shown in Fig. 5 are directly related with the increase in $W_{\text {tot }}$ due to the finer aerosols generated at higher $Q_{1}$ values. It is also interesting to note in this point that no influence of $Q_{1}$ on the $\mathrm{Mg}$ ratio and $\mathrm{Ar}$ intensity has been observed.

Signal enhancement when $Q_{1}$ increases is more important for solutions under $1 \% \mathrm{w} / \mathrm{w}$ (4 times) than for solutions above this value ( 3 times). The reason for these differences may lie in the fact that the increase of the amount of sample evaporated has a higher effect on those solutions that are heated less efficiently (i.e. the more diluted ones). Similar results were obtained using the remaining aqueous and organic solutions evaluated in the present work.

\section{Effect of the nebulizer critical dimensions}

Table 6 shows the Mn net emission signal intensities as a function of the nebulizer critical dimensions (nozzle, $d_{N}$, capillary internal diameters, $d_{\mathrm{C}}$, and capillary length, $l_{\mathrm{C}}$ ) with $1 \% \mathrm{w} / \mathrm{w}$ nitric acid solution. From these results, it
Table 6 Effect of nebulizer critical dimensions on Mn transport rate and net signal intensity for $1 \% \mathrm{w} / \mathrm{w}$ nitric acid solution. $P_{\mathrm{MW}} 290 \mathrm{~W}$; $Q_{1} 1.8 \mathrm{~mL} \mathrm{~min}^{-1}$

\begin{tabular}{|c|c|c|c|c|}
\hline$d_{\mathrm{N}} / \mu \mathrm{m}$ & $l_{\mathrm{c}} / \mathrm{cm}$ & $d_{\mathrm{C}} / \mu \mathrm{m}$ & $\begin{array}{l}\text { Net intensity/ } \\
\text { counts s }\end{array}$ & $W_{\text {tot }} / \mu \mathrm{g} \min ^{-1}$ \\
\hline 150 & 100 & 500 & 395000 & 8.0 \\
\hline 200 & 100 & 500 & 289000 & 6.4 \\
\hline 300 & 100 & 500 & 121000 & 2.3 \\
\hline 200 & 50 & 500 & 266000 & 5.5 \\
\hline 200 & 150 & 500 & 305000 & 7.2 \\
\hline 200 & 100 & 300 & 325000 & 7.0 \\
\hline 200 & 100 & 800 & 216000 & 5.0 \\
\hline
\end{tabular}

appears that the highest intensities are obtained as the internal diameter of the nozzle and/or capillary are decreased. Increasing capillary length also leads to higher intensity values. Plasma excitation conditions were not affected by these changes.

Similar behaviour to those shown in Table 6 have been reported with conventional thermosprays ${ }^{32,38}$ or with previous MWTN $^{19,20}$ designs. For the given experimental conditions, the reduction of the nozzle or PTFE capillary diameter increases the system pressure, since more energy is required for pumping the sample through a narrower tube. This fact leads to a higher velocity for gas and liquid streams and as consequence, more energy is available for aerosol generation (i.e. finer aerosol drop size distribution). Thus, for instance, when a $1 \% \mathrm{w} / \mathrm{w}$ nitric acid solution at $1.8 \mathrm{~mL} \mathrm{~min}^{-1}$ and $290 \mathrm{~W}$ is nebulized, the $D_{50}$ afforded by nozzles with an internal diameter of 200 and $150 \mu \mathrm{m}$ are 13 and $8 \mu \mathrm{m}$, respectively. As regards the capillary length, longer capillaries increase the amount of sample heated by MW, leading to a higher amount of gas. The higher the gas flow, the higher amount of energy available for nebulization. A reduction in aerosol drop size distributions causes the analyte transport to increase and the same happens for the emission signal (Table 6). Similar results were obtained for all the matrices studied.

It is important to point out that the same nozzle has been used for more than one year without any damage and solutions up to $10 \%$ of sodium chloride were nebulized without clogging.

\section{MWTN vs. PN}

Sensitivity. In general terms, the MWTN affords a higher emission signal than a PN. Nonetheless, when diluted nitric acid solutions $(<1 \% \mathrm{w} / \mathrm{w})$ are nebulized at a $Q_{1}$ values under $1.2 \mathrm{~mL} \mathrm{~min}^{-1}$, the emission signal for the $\mathrm{PN}$ is higher (around $20 \%$ ) than that of the MWTN. The signal ratio $\left(I_{\mathrm{MWTN}} I_{\mathrm{PN}}{ }^{-1}\right)$ achieved with inorganic acid can be as high as 4.6, depending on the experimental conditions employed. The higher ratio values are obtained when operating at high $Q_{1}$, high matrix concentration, and small nozzle diameters. Thus, for instance, at $1.8 \mathrm{~mL} \mathrm{~min}^{-1}$ with a nozzle of $200 \mu \mathrm{m}$, the signal ratio for $2 \%$ and $0.25 \% \mathrm{w} / \mathrm{w}$ nitric acid solutions are 3.5 and 2.6, respectively. If sodium chloride solutions are nebulized, the signal ratios range between 1.9 and 2.6. Finally, the signal ratios for organic solutions range from 1.0 to 1.2 due to the high matrix effects observed by the PN with these solvents. 
Table 7 Ratios of the detection limits (PN vs. MWTN) for different lines at optimum sample uptake rate for each system. Nitric acid $2 \%$ w/w. MWTN: $Q_{1} 1.8 \mathrm{~mL} \mathrm{~min}^{-1} ; P_{\mathrm{MW}} 290 \mathrm{~W} ; d_{\mathrm{N}} 150 \mu \mathrm{m} ; l_{\mathrm{C}} 1 \mathrm{~m} ; d_{\mathrm{C}}$ $500 \mu \mathrm{m}$. PN: $0.9 \mathrm{~mL} \mathrm{\textrm {min } ^ { - 1 }}$

\begin{tabular}{lc}
\hline Element & $(\text { LOD })_{\text {PN }}(\text { LOD })_{\text {MWTN }}{ }^{-1}$ \\
\hline $\mathrm{Mn}$ & 8.4 \\
$\mathrm{Mg}$ & 2.9 \\
$\mathrm{Al}$ & 8.6 \\
$\mathrm{Ba}$ & 3.1 \\
$\mathrm{~Pb}$ & 5.9 \\
$\mathrm{Li}$ & 12.7 \\
$\mathrm{Cr}$ & 5.1 \\
$\mathrm{Fe}$ & 5.5 \\
$\mathrm{Co}$ & 5.8 \\
$\mathrm{Cu}$ & 3.7 \\
$\mathrm{Cd}$ & 8.6 \\
$\mathrm{Ca}$ & 7.6 \\
\hline
\end{tabular}

The differences between both nebulizers arise from the aerosol generation process. When a MWTN is employed, sample uptake rate and matrix (i.e. concentration and nature) have a significant effect on the aerosol generation process, and hence in analyte transport and emission signal. However, if a PN is employed, aerosol characteristics and analyte transport rates are less influenced by $Q_{1}$ and sample composition. ${ }^{39}$ Thus, $D_{50}$ increases by $10 \%$ with the PN when $Q_{1}$ is increased from 0.9 to $1.8 \mathrm{~mL} \mathrm{~min}^{-1}$ for $1 \% \mathrm{w} / \mathrm{w}$ nitric acid solution. The MWTN under the same operating condition, gives a decrease of $65 \%$.

The comparison between the primary DSD of both nebulizers reveals that only at acid concentrations over $0.5 \% \mathrm{w} / \mathrm{w}$ and $Q_{1}$ values over $1.2 \mathrm{~mL} \mathrm{~min}^{-1}$ are aerosols generated by the MWTN that are finer than those generated by a PN. Nonetheless, the aerosols generated by the MWTN leave the nebulizer at high temperatures, thus promoting evaporation along the aerosol pathway and reducing its DSD. Tertiary DSD analysis reveals that aerosols generated by the MWTN are finer than those obtained with a PN. The reduction of the tertiary aerosol size and the fact that the analyte is concentrated in the remaining liquid during the aerosol generation give rise to higher transport values. Thus, at $1.8 \mathrm{~mL} \mathrm{~min}^{-1}$ the transport ratio $\left(W_{\text {tot MWTN }} W_{\text {tot PN }}{ }^{-1}\right.$ ) for $2 \%$ and $0.25 \% \mathrm{w} / \mathrm{w}$ nitric acid solution are 3.8 and 2.3 times, similar to the signal ratio observed.

Signal stability. Relative standard deviation (RSD) values for the MWTN depend on the experimental conditions employed and vary for all the lines measured (Table 3), from $1-2 \%$ to $4-7 \%$ in the best and worst sets of operating conditions, respectively. The lower RSDs are obtained using high MW power, matrix concentration and $Q_{1}$ values (i.e. the conditions that give rise to finer aerosols). Thus, for instance, for $0.25 \% \mathrm{w} / \mathrm{w}$ nitric acid solution, when the sample uptake rate is increased from 0.9 to $1.8 \mathrm{~mL} \mathrm{~min}^{-1}$, precision improves from $4-7 \%$ to $1-2 \%$. In general terms, no significant influence of nebulizer critical dimensions has been observed in RSD values. Only when a $300 \mu \mathrm{m}$ internal diameter nozzle is employed are RSD values higher than $5 \%$, due to a poor interaction between vapour and liquid flows. This situation indicates that under normal operating conditions $\left(d_{\mathrm{N}}<300 \mu \mathrm{m}\right)$ the signal stability mainly depends on the microwave heating process.

RSD values obtained with the new MWTN are very similar to those reported in the literature for the previous prototypes. ${ }^{21}$ However, it must be pointed out that lower matrix concentration and a nozzle of larger internal diameter has been employed, clearly indicating that the new prototype shows an improved heating efficiency in comparison with the previous designs.

Limits of detection. Table 7 shows the limits of detection (LODs) ratio between PN and MWTN at the optimum sample uptake rate for each system (i.e., $0.9 \mathrm{~mL} \mathrm{~min}^{-1}$ for $\mathrm{PN}$ and $1.8 \mathrm{~mL} \mathrm{~min}^{-1}$ for MWTN). As it can be observed, when using the MWTN, LODs are improved between 2.5 and 12 times, respectively, to those obtained with the PN.

Following Boumans' approach, ${ }^{25}$ a LOD improvement can be obtained by increasing the signal to background ratio and/or by decreasing the blank RSD. As it has been discussed before, the MWTN shows higher sensitivity than the PN. No significant differences for MWTN and PN in blank intensity and RSD have been observed. The combination of both effects causes the LOD improvements observed in Table 7.

LODs obtained with the present MWTN design are lower than previous ones. Thus, Bordera et al. ${ }^{19,20}$ and Ding et al., ${ }^{21}$ using a MWTN, obtained sensitivities up to 10 times higher than with a PN. However, this enhancement was counterbalanced by higher blank intensities and RSD blank values, leading to LODs 2 to 4 times lower that when using a PN. It is also important to note that previous MWTN designs employed a 2 step desolvation system so as to improve aerosol transport, ${ }^{19,21}$ whereas the current design just makes use of a thermostatized spray chamber. Differences against this new design can be attributed to the more robust design and higher MW heating efficiency afforded by the new prototype. It is expected that results with the new design could be significantly improved using an additional aerosol heating step.

Wash-out. Regardless of matrix nature, no significant differences between the PN and the MWTN on wash-out times were observed. These results are expected since this parameter depends mainly on the characteristics of the spray chamber or desolvation system employed.

Stabilization time. When using the MWTN, any change in the experimental conditions (i.e. $Q_{1}$, MW power or sample matrix) requires a given period of time until it is reflected on the analytical signal. Thus, we define the "stabilization time" as the time needed to obtain a stationary signal when any experimental parameter is modified. This stabilization time does not appear when working with concentric pneumatic nebulizers, since any change in experimental conditions is immediately reflected on the nebulization process. The stabilization times obtained with the current MWTN design goes from 1 to $4 \mathrm{~min}$ depending on the experimental conditions employed. The lower values are obtained when working under those conditions that improve the aerosol generation (i.e. high MW power, $\tan \delta$ or $Q_{1}$ values). It is important to note that 
Table 8 Certified and determined concentration of several elements in a bovine liver sample and recovery values in a spirit sample using the MWTN

\begin{tabular}{|c|c|c|c|}
\hline \multirow[b]{2}{*}{ Element } & \multicolumn{2}{|l|}{ Bovine liver } & \multirow{2}{*}{$\begin{array}{l}\text { Spirit } \\
\text { Recovery }(\%)\end{array}$} \\
\hline & $\begin{array}{l}C_{\text {certified/ }} \\
\mathrm{mg} \mathrm{kg}^{-1}\end{array}$ & $\begin{array}{l}C_{\text {experimental }} / \\
\mathrm{mg} \mathrm{kg}^{-1}\end{array}$ & \\
\hline $\mathrm{Zn}$ & $139 \pm 2$ & $138 \pm 3$ & $98 \pm 3$ \\
\hline $\mathrm{Cu}$ & $277 \pm 5$ & $262 \pm 11$ & $96 \pm 3$ \\
\hline $\mathrm{Mn}$ & $11.1 \pm 0.3$ & $11.3 \pm 0.6$ & $98 \pm 2$ \\
\hline
\end{tabular}

when using optimum aerosol generation conditions, the stabilization time is very similar to the wash-out time. For this reason, the time required to perform an analysis mainly depends on the spray chamber design and is scarcely affected by the MWTN.

\section{Analysis of samples}

The analytical performance of current MWTN has been evaluated by analyzing two samples with very different matrices; a certified bovine liver and a spirit of $45 \%$ ethanol content. As far as we know, there is no literature about the analysis of real samples using an MWTN, probably due to the lack of robustness of previous designs. The bovine liver sample was previously digested by using a microwave oven, whereas the spirit sample was analyzed directly without any sample pre-treatment. The alcoholic sample was spiked with $10 \mu \mathrm{g} \mathrm{L}^{-1}$ of multielemental standard ICP-IV to perform a recovery test, since certified element concentrations were not available. Both samples were spiked with $10 \mu \mathrm{g} \mathrm{L}^{-1}$ of monoelemental reference Sc solution as an internal standard. Three replicates of each sample were carried out.

Table 8 shows the concentration values obtained for several elements in the bovine liver, as well as recovery values for the spirit sample with the MWTN. Concentration values for the bovine liver sample are not statistically different from the certified values for a confidence level of $95 \%$. As regards the spirit sample, the recovery values have been close to $100 \%$, with a confidence interval up to $3 \%$ at a confidence level of $95 \%$. These results point out that MWTN can be employed as an efficient sample introduction system to perform routine analysis with samples of a different nature.

\section{Conclusions}

The new MWTN has been successfully evaluated for liquid sample introduction in ICP-AES. It overcomes the drawbacks shown by previous designs, thus giving rise to a robust and highly versatile sample introduction system. This prototype is closer to fulfilling ideal nebulizer requeriments than previous prototypes. The $\mathrm{TM}_{010}$ cavity employed improves $\mathrm{MW}$ heating efficiency, allowing nebulization of $0.25 \mathrm{w} / \mathrm{w}$ acidic solutions or $40 \% \mathrm{w} / \mathrm{w}$ alcoholic solutions. In addition, nozzle design is more robust and reproducible, reducing liquid leaks and signal instabilities. Both factors allow the improvement of LODs up to 12 times by respect to a PN. Aerosol characteristics for inorganic solutions above $2 \%$ are independent of matrix composition, matrix effects being related just to plasma energetic conditions.
MWTN can be successfully employed for the analysis of samples of different natures.

\section{Acknowledgements}

G. Grindlay thanks the University of Alicante for the $\mathrm{PhD}$ fellowship.

\section{References}

1 J. Mora, S. Maestre, V. Hernandis and J. L. Todolí, TrAC, Trends Anal. Chem., 2003, 22, 123.

2 X. Zhang, D. Chen, R. Marquardt and J. A. Koropchack, Microchem. J., 2000, 66, 17.

3 S. K. Luo and H. Berndt, Spectrochim. Acta, Part B, 1994, 49, 485.

4 M. A. Tarr, G. X. Zhu and R. F. Browner, Appl. Spectrosc., 1991, $45,1424$.

5 R. I. Botto and J. J. Zhu, J. Anal. At. Spectrom., 1994, 9, 905.

6 J. Mora, A. Canals and V. Hernandis, Spectrochim. Acta, Part B, 1996, 51, 1535.

7 J. Mora, J. L. Todolí, A. Canals and V. Hernandis, J. Anal. At. Spectrom., 1997, 12, 445.

8 M. T. C. de Loos-Vollebregt, R. Peng and J. J. Tiggleman, J. Anal. At. Spectrom., 1991, 6, 165.

9 K. A. Vermeiren, C. Vandecasteele and R. Dams, J. Anal. At. Spectrom., 1988, 3, 571.

10 J. A. Koropchak, M. Veber and J. Herries, Spectrochim. Acta, Part $B, 1992,47,825$.

11 M. Veber, J. A. Koropchak, T. S. Conver and J. Herries, Appl. Spectrosc., 1992, 46, 1525.

12 J. L. Luque-García and M. D. Luque de Castro, $\operatorname{Tr} A C$, Trends Anal. Chem., 2003, 22, 90.

13 B. Rosenkranz and J. Bettmer, TrAC, Trends Anal. Chem., 2000, 19, 138.

14 L. Gras, J. Mora, J. L. Todolí, A. Canals and V. Hernandis, Spectrochim. Acta, Part B, 1999, 54, 469.

15 L. Gras, J. Mora, J. L. Todolí, A. Canals and V. Hernandis, Spectrochim. Acta, Part B, 1999, 54, 1321.

16 J. Mora, A. Canals, V. Hernandis, E. H. Van Veen and M. T. C. de Loos-Vollebregt, J. Anal. At. Spectrom., 1998, 13, 175.

17 G. Grindlay, S. Maestre, J. Mora, V. Hernandis and L. Gras, J. Anal. At. Spectrom., 2005, $20,405$.

18 G. Grindlay, S. Maestre, L. Gras and J. Mora, J. Anal. At. Spectrom., 2006, 21, 1403

19 L. Bordera, J. L. Todolí, J. Mora, A. Canals and V. Hernandis, Anal. Chem., 1997, 69, 3578.

20 L. Bordera, PhD thesis, University of Alicante, Alicante, 1998.

21 L. Ding, F. Liang, Y. Huan, Y. Cao, H. Zhang and Q. Jin, J. Anal. At. Spectrom., 2000, 15, 293.

22 F. Liang, PhD thesis, Jilin University, Changchun, 1997.

23 S. J. Hill, J. Hartley and L. Ebdon, J. Anal. At. Spectrom., 1992, 7, 23.

24 Microwave digestión applications manual (MSP-1000), CEM publishing, Matthews, 1994.

25 P. W. J. M. Boumans, Spectrochim. Acta, Part B, 1991, 46, 431.

26 S. Maestre, J. Mora, J. L. Todolí and A. Canals, J. Anal. At. Spectrom., 1999, 14, 61.

27 C. Pan, G. Zhu and R. F. Browner, J. Anal. At. Spectrom., 1990, 5, 537.

28 J. M. Mermet, Anal. Chim. Acta, 1991, 250, 85.

29 E. H. van Veen and M. T. C. de Loos-Vollebregt, J. Anal. At. Spectrom., 1999, 14, 831.

30 I. Novotny, J. C. Farinas, J. L. Wan, E. Poussel and J. M. Mermet, Spectrochim. Acta, Part B, 1996, 51, 1517.

31 J. L. Todolí and J. M. Mermet, J. Anal. At. Spectrom., 2002, 17, 211.

32 J. Mora, A. Canals and V. Hernandis, Spectrochim. Acta, Part B, 1996, 51, 1535.

33 A. Zlotorzynski, Crit. Rev. Anal. Chem., 1995, 25, 43.

34 J. L. Todolí, L. Gras, V. Hernandis and J. Mora, J. Anal. At. Spectrom., 2002, 17, 142.

35 J. L. Todolí and J. M. Mermet, Spectrochim. Acta, Part B, 1999, $\mathbf{5 4}, 895$. 
36 B. L. Hayes, in Microwave Synthesis, CEM publishing, Matthews, 2002.

37 Handbook of Chemistry and Physics, ed. R. C. Weast, D. R. Lide, M. J. Astle and W. Beyer, CRC press, Boca Raton, 1989.
38 J. A. Koropchak and H. Aryamanya-Mugisha, Anal. Chem., 1988, 60, 1838.

39 J. M. Cano, J. L. Todoli, V. Hernandis and J. Mora, J. Anal. At. Spectrom., 2002, 17, 57. 